\title{
USO DE EXTRATOS NATURAIS NO CONTROLE DE INSETOS, COM ÊNFASE EM MOSCAS-DAS-FRUTAS (DIPTERA: TEPHRITIDAE)
}

\begin{abstract}
S. Braga e Silva ${ }^{1}$, M.E. Sato ${ }^{2}$, A. Raga ${ }^{2}$
'Bióloga, Mestranda do Programa de Pós-Graduação em Sanidade, Segurança Alimentar e Ambiental no Agronegócio, Instituto Biológico, Campinas, SP, Brasil. E-mail: sarabraga321@gmail.com. ${ }^{2}$ Engenheiro-Agrônomo, Pesquisador Científico VI, Instituto Biológico, Centro Avançado de Pesquisa em Proteção de Plantas e Saúde Animal, Alameda dos Vidoeiros, 1097, Bairro Gramado, CEP 13101-680, Campinas, SP, Brasil. E-mail: mesato@biologico.sp.gov.br; adalton@biologico.sp.gov.br
\end{abstract}

\section{RESUMO}

No Brasil, o controle de moscas-das-frutas é baseado principalmente na utilização de inseticidas na parte aérea da planta, nas formas de cobertura total e/ou de iscas tóxicas. As duas principais espécies de moscas-das-frutas que ocorrem no Brasil são Ceratitis capitata (Wiedemann) e Anastrepha spp. (Diptera: Tephritidae). Os danos ambientais imediatos e os efeitos adversos de longo prazo causados pelo uso de agrotóxicos revelam a importância do desenvolvimento de alternativas para o manejo sustentável de pragas de insetos-praga, incluindo moscas-das-frutas. A flora brasileira é muito rica em espécies de plantas que possuem substâncias químicas com atividade inseticida. $\mathrm{O}$ uso de extratos vegetais é uma das formas de se utilizar as plantas com bioatividade no controle de pragas agrícolas. Com base na literatura, o presente trabalho teve como objetivo descrever os principais modos de ação de alguns grupos de metabolitos secundários que apresentam características repelentes, deterrentes alimentares e de oviposição, inibidores de crescimento, esterilizantes e toxinas, encontrados nas plantas contra moscas-das-frutas e outras espécies de insetos fitófagos, e o potencial de aplicações dessas substâncias no manejo de pragas e vetores.

PALAVRAS-CHAVE: insecta, extrato botânico, efeito repelente, mortalidade, manejo. 


\section{ABSTRACT}

\section{USE OF NATURAL EXTRACTS IN INSECT CONTROL, WITH EMPHASIS IN FRUIT FLIES (DIPTERA: TEPHRITIDAE).}

In Brazil, the controlling of fruit flies is essentially based on the use of insecticides by cover spray or using toxic baits. The two main species of fruit flies occurring in Brazil are Ceratitis capitata (Wiedemann) and Anastrepha spp. (Diptera: Tephritidae). The immediate and the long-term environmental damage caused by the use of pesticides reveal the importance of developing alternatives for the sustainable management of insect pests, including fruit flies. The Brazilian flora is very rich in species of plants that have chemical substances with insecticidal activity. The use of plant extracts is one of the ways how to use bioactive plants to control agricultural pests. Based on the literature, the present work aimed to describe the main modes of action of some groups of secondary metabolites that exhibit characteristics of feeding and oviposition deterrent activities, growth inhibitors, sterilizants and toxins found in plants against fruit flies and other species of phytophagous insects, and the potential of its applications in the management of pests and vectors.

KEYWORDS: insecta, botanical extract, deterrent effect, mortality, management.

\section{INTRODUÇÃO}

O modelo agrícola adotado no Brasil está fortemente vinculado ao uso de agrotóxicos, isso, considerando que a agricultura do país se concentra em um modelo de desenvolvimento voltado a ganhos de produtividade (FERREIRA, 2015).

As moscas-das-frutas (Diptera: Tephritidae) estão entre as principais espécies de insetos-praga da fruticultura mundial. $O$ ataque de moscas-das-frutas causa prejuízos diretos e indiretos à fruticultura (SOUZA-FILHO et al., 2000; ZUCCHI, 2000; MONTES; RAGA, 2006).
No Brasil, o controle de moscas-das-frutas, na propriedade, é baseado principalmente na utilização de inseticidas na parte aérea da planta, nas formas de cobertura total e/ou de iscas tóxicas.

Os tempos letais $50 \%\left(\mathrm{TL}_{50}\right)$ da maioria dos ingredientes ativos registrados foram determinados em laboratório, para as duas principais espécies de moscas-das-frutas que ocorrem no Brasil (RAGA; SATO, 2016). Ceratitis capitata (Wiedemann) (Diptera: Tephritidae) e Anastrepha spp. são sensíveis à maioria dos inseticidas químicos. No 
entanto, comprovou-se a existência de populações de $C$. capitata resistentes ao malation em pomares na Espanha, e mortalidade de inimigos naturais e insetos benéficos causados por espinosade e diazinon (MAGAÑA et al., 2007).

Devido aos efeitos adversos causados pelos inseticidas sintéticos, como a seleção de populações resistentes de insetos para a maioria desses produtos químicos (BRATTSTEN et al., 1986; ZETTLER; CUPERUS, 1990), envenenamento de cadeias alimentares, morte de organismos não alvos, alta toxicidade a mamíferos, danos ambientais e efeitos adversos de longo prazo ao homem, existe uma demanda emergente de inseticidas/pesticidas botânicos para controlar insetos-praga (ISMAN; MACHIAL, 2006), podendo ser uma alternativa viável para o manejo sustentável de pragas.

A flora brasileira é muito rica em espécies de plantas que possuem substâncias químicas com atividade inseticida. A utilização dos inseticidas de origem vegetal merece destaque entre os métodos alternativos ao controle químico convencional, pelos aspectos de segurança e pela conservação do equilíbrio do agroecossistema (FERRACINI et al., 1990).

O uso de extratos vegetais é uma das formas de se utilizar as plantas com bioatividade no controle de pragas agrícolas (KOSHIYA; GHELANI, 1993; BALLESTA-ACOSTA et al., 2008). Os com- postos presentes nas plantas apresentam características tóxicas, repelentes, deterrentes de alimentação e oviposição, inibidoras de crescimento e esterilizantes, formando uma defesa química contra insetos e outros organismos fitófagos (GUPTA et al., 2001; SAAD et al., 2017).

Essas substâncias químicas podem ser agrupadas em cinco grupos químicos majoritários: compostos nitrogenados (principalmente alcaloides), terpenoides, fenólicos, inibidores de proteinase e reguladores de crescimento (SAXENA, 1989; MAIA; MOORE, 2011). Os princípios ativos dos inseticidas botânicos são compostos resultantes do metabolismo secundário das plantas, sendo acumulados em pequenas concentrações nos tecidos vegetais (VIEGAS-JUNIOR, 2003; ALMEIDA et al., 2015; MOREIRA et al., 2006), os quais podem ser encontrados em raízes, caules, folhas, sementes e frutos (MIGUEL, 2000).

Os inseticidas botânicos possuem ação direta sobre insetos, são seletivos e apresentam baixa persistência no ambiente, possibilitando o controle de pragas com menor número de aplicações de inseticidas sintéticos de amplo espectro (ZERA; HARSHMAN, 2001; SANTOS et al., 2012). Os inseticidas botânicos são uma alternativa viável como fonte de substâncias menos tóxicas e cujo potencial de ação contra fitopatógenos é demonstrada pela literatura (BONALDO et al., 2004; MIGUEL et al., 2006). 


\section{HISTÓRICO EVOLUTIVO DA DEFESA DE PLANTAS A INSETOS}

A evolução das plantas transformou o ambiente terrestre em um recurso altamente valioso para a comunidade herbívora. Nos ecossistemas naturais, plantas e insetos são apenas alguns dos organismos vivos que estão interagindo continuamente de maneira complexa (MELLO; SILVA-FILHO, 2002). Esses dois grupos de organismos estão intimamente associados, uma vez que os insetos executam várias atividades benéficas, incluindo defesa e polinização, entre outras, enquanto as plantas fornecem abrigo, alimento e locais de oviposição, os três principais fatores demandados pelos insetos para sua proliferação (PANDA; KHUSH, 1995). Por outro lado, o ataque de insetos herbívoros, dependendo da intensidade, pode ser extremamente prejudicial para as plantas, levando-as à morte.

Algumas plantas, ao longo de sua evolução, desenvolveram sua própria defesa química contra os insetos herbívoros, sintetizando metabólicos secundários com propriedades inseticidas; isto é, com atividade tóxica contra os insetos ou que causam sua morte por outros modos de ação, ou mesmo sua repelência (MENEZES, 2005).

As espécies vegetais bem-sucedidas tipicamente sintetizam uma ampla gama de compostos de defesa moderadamente tóxicos ou um pequeno número de substâncias altamente tóxicas (RATTAN, 2010). Os insetos herbívoros se alimentam de uma grande variedade de espécies de plantas, e podem encontrar substâncias tóxicas com efeitos relativamente inespecíficos e uma variedade de moléculas alvos (MILLS et al., 2004). A constituição desses alvos varia de proteínas (enzimas, receptores, canais iônicos, proteínas estruturais), ácidos nucleicos, biomembranas a metabólitos secundários, com interações específicas ou não específicas e outros componentes celulares (HARBORNE, 1993).

Os metabólitos secundários podem interferir em certos componentes vitais do sistema de sinalização celular, ou em enzimas vitais, atuando no sistema nervoso (ex.: síntese de neurotransmissores, armazenamento, liberação, ligação e reabsorção; ativação de receptores e enzimas envolvidas na tradução de sinais) e bloqueando vias metabólicas (WINK, 2000). O conhecimento das propriedades químicas desses compostos é necessário para a segurança e economia do seu uso na agricultura (CASIDA; QUISTAD, 1998).

O comportamento dos insetos, ao longo do seu desenvolvimento (ontogenético), é modelável, podendo ser afetado por muitos fatores ambientais, como disponibilidade de alimentos e hospedeiros, qualidade do hospedeiro, presença de machos, fatores abióticos, inimigos naturais etc. (WHEELER, 1996; BOGGS, 2009). A disponibilidade de alimentos e hospedeiros destaca-se entre esses fatores, devido às diversas necessidades dos insetos e suas interações com as plantas (ZERA; HARSHMAN, 2001). 
O caminho evolutivo que leva à especialização de herbívoros é um problema complexo, e os fatores envolvidos na seleção e estabelecimento em uma planta hospedeira são altamente diversificados, com padrões que variam desde o extremo conservadorismo (WEHLING; THOMPSON, 1997) até a extrema maleabilidade (FITT, 1986). No caso de moscas-das-frutas (Diptera: Tephritidae), o conservadorismo é exemplificado na subfamília Tephritinae, que é quase exclusivamente associada com espécies de Asteraceae (FARRELL, 1992). Mas, em Tephritidae, também há evidências de evolução, com espécies atacando uma ampla gama de plantas não relacionadas (ALUJA; NORRBOM, 2000).

Em termos gerais, são duas as principais forças que direcionam os processos evolutivos para uma ampla gama de hospedeiros: processos fitoquímicos coevolutivos entre plantas e herbívoros (BECERRA, 1997) e pressão seletiva por inimigos naturais generalistas (BERNAYS; GRAHAM, 1988).

\section{TIPOS DE MECANISMOS DE DEFESA DAS PLANTAS}

Plantas e insetos interagem em um processo evolutivo que ocorre há aproximadamente 400 milhões de anos. Essas plantas produzem seus compostos químicos para fins de defesa de duas formas diferentes: 1) produção de substâncias constitutivas para repelir herbívoros pela sua toxicidade direta ou pela redução da digestibilidade dos tecidos vegetais; 2) através de indução da síntese de substâncias de defesa em resposta aos danos nos tecidos, causados por herbí- voros (MELLO; SILVA-FILHO, 2002).

Dessa forma, as plantas desenvolveram e ainda estão em constante desenvolvimento de diversos tipos de defesa, principalmente de natureza química e morfológica, para superar os ataques de organismos fitofagos (STOWE, 1998; BOIÇA-JÚNIOR et al., 2015); os quais conferem a expressão de uma ou mais categorias de resistência (HARUTA et al., 2001)

\section{O QUE SÃO INSETICIDAS BOTÂNICOS? QUAIS OS PRINCÍPIOS ATIVOS E MODO DE AÇÃO?}

Os inseticidas botânicos são produtos derivados de plantas ou partes das mesmas, podendo ser o próprio material vegetal, normalmente moído até ser reduzido a pó, ou seus produtos derivados por extração aquosa ou por solventes orgânicos, tais como álcool, éter, acetona, clorofórmio ou pela destilação (VENDRAMIM; CASTIGLIONI, 2000). Na década de 1940, o comércio e a pesquisa da rotenona e de outras plantas com propriedades inseticidas eram bastante de- 
senvolvidos. Desde então, até o final do século 20 , pouco havia sido acrescentado em relação ao acervo de plantas com esse potencial (WIESBROOK, 2004).

As plantas inseticidas mais promissoras encontram-se nas famílias Meliaceae, Rutaceae, Asteraceae, Annonaceae, Labiatae e Canellaceae (JACOBSON, 1989; FERNANDES et al., 2005).

Os primeiros inseticidas botânicos que dominavam o mercado eram as piretrinas e a rotenona, as piretrinas naturais, extraídas de Chrysanthemum cinerariaefolium Vis. (Asteraceae), e a rotenona, derivada de Derris spp. e Lonchocarpus spp. (Fabaceae). Outros inseticidas botânicos usados em pequena escala são os alcaloides, como a nicotina de Nicotiana tabacum L. (Solanaceae), quassin de Quassia amara L. (Simaroubaceae), rianodina de Ryania speciosa Vahl (Flacourtiaceae) e sabadila de SchoenocauIon officinale (Schltdl. \& Cham.) (Liliaceae) (JACOBSON, 1989;VENDRAMIM; CASTIGLIONI, 2000; KATHRINA; ANTONIO, 2004; WIESBROOK, 2004). O nim, extraído de Azadirachta indica A. Juss. (Meliacae) tem sido uma das plantas mais estudadas para uso como inseticida botânico nos últimos anos (WIESBROOK, 2004).

Plantas como o fumo, crisântemo, derris, anona e riania, com substâncias bioativas inseticidas, apresentam graus diferenciados de toxicidade para o homem e mamíferos, recomendando-se o seu uso com precaução (MENEZES, 2005). Isso é devido ao fato de que infor- mações disponíveis sobre a caracterização, o modo de ação, a toxicologia e os efeitos no ecossistema, para a maioria dos inseticidas botânicos, são ainda escassas, embora a maioria seja utilizada há mais de uma década (MILLS et al., 2004). O nim tem sido a única planta, até o presente momento, a ser pesquisada plenamente, comprovando-se que é medicinal, não tóxica e contém um grupo poderoso de substâncias inseticidas (MARTINEZ, 2002).

Algumas substâncias ou compostos de plantas podem atuar de várias formas, especialmente quando é um complexo químico o responsável por sua ação não benéfica sobre o inseto (UPADHYAY, 2016). A ação tóxica de muitos extratos botânicos provém da ação de seus ingredientes ativos no sistema nervoso central dos insetos, interferindo na transmissão (sináptica ou axônica) normal dos impulsos nervosos, sendo denominados de neurotóxicos (GUEDES, 2001). Podem causar a morte do inseto por intoxicação, mas, às vezes, são repelentes (fazem com que os insetos se afastem da planta, prevenindo a alimentação ou oviposição na mesma) ou inibem a alimentação (ALKOFAHI et al., 1987).

Alguns inseticidas botânicos podem agir no sistema neuroendócrino, interferindo nos processos normais da troca de tegumento (ecdise) e/ou metamorfose, sendo denominados de reguladores de crescimento, ou podem interferir no metabolismo respiratório das células, interferindo na síntese de ATP (JACOBSON, 1975). Moléculas presentes em determi- 
nados tipos de extratos naturais são capazes de atuar no sistema hormonal dos insetos, ou melhor, nas glândulas anexas ao cérebro, onde se regula a biossíntese e a liberação dos hormônios da ecdise (ecdisona e 20-hidroxiecdisona) através das glândulas protorácicas (MENEZES, 2005). Como consequência, não ocorre a biossíntese dos hormônios, o que impossibilita os passos normais da troca de tegumento ou a maturação dos ovos (KATHRINA; ANTONIO, 2004).

Os primeiros estádios larvais e das ninfas dos insetos afetados por extratos vegetais perduram, às vezes, por três semanas em um mesmo estádio, até que morram, enquanto que o quarto e o quinto estádios larvais podem conseguir empupar, mas os adultos emergem com as asas deformadas ou outras deficiências (GOVINDARAJAN, 2010).

O modo de ação dos inseticidas pode ser por contato ou ingestão. Os inseticidas que agem por contato caracterizam-se pela sua atuação principal, quando é absorvido através do tegumento do inseto (KABERA et al., 2011). Essas substâncias podem atingir o sistema nervoso central dos insetos, através da penetração por qualquer parte da superfície do corpo ou pelas vias respiratórias, causando a morte do organismo alvo (LIMA et al., 2009; CORRÊA; SALGADO, 2011).

As substâncias repelentes atuam principalmente por contato, agindo nos quimiorreceptores dos insetos, afetando o seu comportamento (CORRÊA; SALGADO, 2011).
As substâncias que atuam por ingestão penetram no organismo por via oral, podendo afetar a capacidade de digestão e aproveitamento de alimentos, a biossíntese de hormônios (ex.: ecdisona) ou a formação da camada de quitina da cutícula do inseto (BEGUM et al., 2010).

As substâncias deterrentes alimentares atuam por ingestão e provocam redução na atividade do tubo digestivo, com perda de estímulo para alimentação, levando o inseto à morte por inanição (ROARK, 1947). Esses compostos agem principalmente sobre organismos herbívoros e, assim, não apresentam toxicidade aos seres humanos, e quando apresentam algum efeito tóxico, geralmente, isso é devido à presença de outras substâncias da planta ou a outros compostos utilizados na formulação, no caso de inseticidas botânicos formulados (BALLEST et al., 2008).

Os inseticidas que agem no processo de produção de energia, ou respiração celular, ligam-se às enzimas respiratórias (ex.: fosfoglicomutase, desidrogenase succínica, citocromo oxidase) que ocorrem nas mitocôndrias e inibem sua atividade (UPADHYAY, 2016). Eles atuam na cadeia de transporte de elétrons dentro das mitocôndrias, onde inibem a oxidação do FAD (Flavina Adenina Dinucleotídeo) (KATHRINA; ANTONIO, 2004). Além disso, podem causar a inibição de enzimas que catalisam a degradação de glicose, como fosfatases, peroxidases e catalases (PARÉ; TUMLINSON, 1999). 
Essas toxinas também podem paralisar a respiração celular, impedindo a oxidação de substratos específicos (ex.: do complexo I da cadeia respiratória), ou atuar como desacoplador da fosforilação oxidativa, inibindo a síntese de ATP (ALKOFAHI et al., 1987).

Alguns produtos naturais tais como os óleos essenciais podem bloquear a respiração de larvas e adultos de insetos (HUSSEIN, 2005). Os óleos essenciais

\subsection{Alcaloides}

Comumente encontrados nas espécies vegetais, esses produtos químicos não são voláteis e podem ser utilizados como repelentes pela queima de material vegetal, para criar uma fumaça inseticida que repele os insetos por toxicidade direta (RATTAN, 2010). Alcaloides são encontrados em grandes quantidades em muitos membros das famílias Berbe-

\subsection{Piretro}

O piretro refere-se às oleorresinas, que são extraídas das flores secas de crisântemos (gênero Chrysanthemum), que contêm os princípios ativos piretrinas, cinerinas e jasmolinas, que são dos tipos p I e II (incorporam o álcool piretrolona), são as mais abundantes e representam maior parte da atividade inseticida (MATSUMURA, 1976). A ação inseticida das piretrinas é caracterizada por um efeito rápido, particularmente em insetos voadores, além de hiperatividade atuam como venenos respiratórios, podendo formar uma película de cobertura em meio aquoso e impedir a respiração de larvas de diferentes espécies de mosquitos (KONSTANTOPOULOU et al., 2002). Além disso, esses óleos são usados para matar cupins em túneis subterrâneos, devido à sua elevada pressão de vapor e capacidade de penetração nos tecidos (BLÄSKE et al.2003; PAVELA et al., 2016).

ridaceae, Fabaceae, Solanaceae e Ranunculaceae, todas elas usadas extensivamente como repelentes tradicionais de insetos (SECOY; SMITH, 1983;). Seu modo de ação varia, mas a maioria afeta o sistema nervoso, atuando nos receptores de acetilcolina ou nos canais de sódio da membrana do axônio (ROEDER, 1994).

e convulsões na maioria dos insetos (ISMAN; MACHIAL, 2006).

A ação neurotóxica das piretrinas, que modulam (prolongam) o tempo de abertura dos canais de sódio nos insetos, provoca hiperexcitabilidade do sistema nervoso central, devido à transmissão contínua e descontrolada de impulsos nervosos, resultando em um efeito de choque (knockdown), seguido de perda da capacidade locomotora, paralisia e morte (BUSS; PARK-BROWN, 2002; 
KATHRINA; ANTONIO, 2004). O mecanismo de ação das piretrinas é similar ao do DDT (ISMAN, MACHIAL, 2006).

Com maior estabilidade e potencial inseticida, a obtenção dos piretroides é

\subsection{Rotenona}

Os rotenoides são compostos flavonoídicos extraídos das leguminosas tropicais Derris e Lonchocarpus (Fabaceae), que no Brasil são conhecidas por timbó. Os componentes ativos são encontrados nas raízes e nos caules das plantas, entre eles, o alcaloide rianodina (GUEDES, 2001). O principal princípio ativo encontrado nas raízes é o isoflavonoide rotenona, que possui moderada toxicidade para mamíferos em virtude da reduzida absorção dérmica e do rápido metabolismo (PACAN; LOUSTALOT, 1949).

A toxicidade aguda da rotenona pura para mamíferos ( $\mathrm{DL}_{50}$ por via oral em ratos é de $132 \mathrm{mg} / \mathrm{kg}$ ) é comparável a de DDT e outros inseticidas sintéticos. No caso de produtos formulados, a toxicidade geralmente é menor (PACAN; LOUSTALOT, 1949).

A rotenona atua como um forte inibidor do complexo I da cadeia respiratória mitocondrial. O mecanismo de ação inegavelmente o melhor exemplo de êxito no uso de inseticidas botânicos como fonte para a obtenção de produtos efetivos contra um largo espectro de insetos (BOIÇA-JÚNIOR et al., 2015).

(MOA) compreende a inibição da transferência de elétrons dos centros de ferro-enxofre no complexo I para a ubiquinona, levando a um bloqueio da fosforilação oxidativa, com síntese limitada de ATP (HEINZ et al., 2017), o que leva à redução das taxas respiratória e cardíaca (MATSUMURA, 1976; GALLO et al., 2002; TADA-OIKAWA et al., 2003; KATHRINA; ANTONIO, 2004).

Os sintomas em insetos afetados por rotenona incluem a rápida parada de alimentação, a perda das funções locomotoras, a paralisia e a morte rápida (várias horas a poucos dias após a exposição). Todavia, ela age mais lentamente do que a maioria dos inseticidas botânicos (NIRMA et al., 2012). A rotenona apresenta amplo espectro de ação por contato e ingestão, mas decompõe-se rapidamente pela ação da luz e calor, apresentando curto período residual (uma semana a menos) (UPADHYAY, 2016).

\subsection{Rianodinas}

São alcaloides provenientes de plantas de Ryania speciosa (Salicaceae), na qual exercem um alto poder inseticida (DI RENZO, 2009). As suas proprieda-

des permitiram a identificação e a caracterização molecular de uma família de canais de liberação de $\mathrm{Ca}^{2+}$ intracelular, comumente denominados receptores de 
rianodina (RYR) (KUNA; HEAL, 1948).

Os canais de cálcio representam um novo alvo no controle de insetos. A homeostase do cálcio é um componente-chave nas funções de multiplicação celular, com particular importância no controle muscular. A rianodina se prende aos receptores de rianodina e perturba o fluxo de cálcio, tornando o canal parcialmente aberto e levando a uma liberação descontrolada das reservas de cálcio

\subsection{Nicotina}

A nicotina, um alcaloide extraído de algumas espécies do gênero Nicotiana (Solanaceae), age no sistema nervoso dos insetos, competindo com o neurotransmissor acetilcolina, com efeito de contato, ingestão e repelência (TAN et al., 2007; TOMIZAWA; CASIDA, 2009). É uma substância estruturalmente semeIhante à acetilcolina, o principal neurotransmissor excitatório no sistema nervoso central dos insetos (TAN et al., 2007; TONG et al., 2013).

A nicotina é, portanto, um agonista (equivalente) da acetilcolina, e, assim, imita a sua ação, competindo com a acetilcolina pelos seus receptores presentes na membrana pós-sináptica (HERMSMEIER; SCHITTKO; BALDWIN, 2001). Ao contrário da ligação natural da acetilcolina com esses receptores, a ligação
(LAHM et al., 2005). A perda de capacidade de regular o cálcio leva à letargia, à cessação da alimentação e, por fim, à morte (TEIXEIRA; ANDALORO, 2013). A rianodina foi usada no passado como um inseticida natural, mas a sua alta toxicidade observada em mamíferos impediu a continuação do seu uso a campo, pois apresenta uma $\mathrm{DL}_{50}$ para humanos de $143 \mathrm{mg} / \mathrm{kg}$ (NAUEN, 2006).

dos mesmos com a nicotina é persistente, uma vez que é insensível à ação da enzima acetilcolinesterase (enzima responsável pela degradação da acetilcolina) (DEDERER et al., 2011).

A ativação dos receptores de acetilcolina pela nicotina é, portanto, prolongada de modo anormal, causando hiperexcitabilidade do sistema nervoso central, devido à transmissão contínua e descontrolada de impulsos nervosos, causando tremores e paralisia (MATSUMURA, 1976; KATHRINA; ANTONIO, 2004).

A partir do estudo da estrutura química da nicotina, foi possível sintetizar os inseticidas neonicotinoides, um dos grupos recentes de inseticidas, amplamente utilizados na agricultura para controle de insetos sugadores (DEDERER et al., 2011). 


\subsection{Quassinoides}

São alcaloides presentes nos tecidos de Quassia amara L. (Simaroubaceae) que são usados no preparo de inseticidas (EVANS; RAJ, 1991; DAIDO et al., 1993). Sua casca contém muitos constituintes e fitoquímicos de sabor amargo, sendo 50 vezes mais amargo do que o quinino (GARCIA et al., 1996).

Apresentam ação de contato e ingestão, mas também têm ação sistêmica quando os extratos são preparados a partir das raízes, sendo os princípios transportados até as folhas, onde agem

\subsection{Sabadila}

Pó extraído das sementes de Schoenocaulon officinale (Liliaceae), contém vários alcaloides, principalmente cevadina, veratridina e 3-veratroil. A sua atividade inseticida provém da fração de alcaloides, a qual se constitui de $3-6 \%$ do extrato. Os alcaloides lipofílicos cevadina e veratridina são os de maior atividade inseticida, sendo que veratridina tem o maior potencial inseticida (KATHRINA; ANTONIO, 2004).

\subsection{Limonoides}

Limonoide também é conhecido por meliacina, devido ao seu sabor amargo. Dentre as espécies de plantas da família Meliaceae que possuem propriedades de controle de pragas, o nim e o cinamomo (Melia azedarach L.) são as espécies mais promissoras do ponto de vista como veneno estomacal contra os insetos, especialmente os sugadores (MANCEBO et al., 2000). Esses alcaloides são altamente solúveis em água e, por ter ação sistêmica, podem ser usados como extratos aquosos aplicados no solo (ROARK, 1947). Além disso, quassin inibe a atividade da tirosinase. Sabendo-se que essa enzima está diretamente envolvida na esclerotização da cutícula é sugerido que quassin age como um larvicida por inibir o desenvolvimento da cutícula (EVANS; KALEYSA, 1992).

Sabadila apresenta amplo espectro de ação de contato e ingestão, afetando a transmissão axônica dos impulsos nervosos, de modo similar às piretrinas (IKBAL et al., 2006). Essas substâncias atuam nas membranas das células nervosas, causando perda de função, paralisia dos insetos e morte em pouco tempo (SANDOVAL-MOJICA; CAPINERA, 2011).

entomológico (SCHMUTTERER, 1990). Diversos limonoides têm sido identificados nas folhas, caule, frutos e sementes. Entretanto, o composto azadiractina, de ocorrência restrita nessas espécies, tem maior potencial de uso contra os insetos (SALLES; RECH, 1999). 
A azadiractina pode causar diversos efeitos sobre os insetos, como atividades fagoinibidora e comportamental (STARK et al., 1990). Também interfere no sistema neuroendócrino, comportando-se como análogo aos principais hormônios envolvidos na regulação do desenvolvimento e reprodução dos insetos, provocando anormalidades morfológicas e mortalidade (ISMAN; MACHIAL, 2006). $A$ azadiractina atua interferindo no fun-

\section{9. Óleos Essenciais}

São substâncias constituídas por uma variedade de misturas de componentes de alta volatilidade, basicamente monoterpenos, sesquiterpenos e fenilpropanoides, como as principais classes químicas envolvidas (EL-SHAZLY; HUSSEIN, 2004), que foram consideradas altamente eficazes para repelir insetos (PAVELA et al., 2016). São geralmente armazenados em glândulas específicas em diversos órgãos vegetais, os quais são responsáveis pelo cheiro nas plantas aromáticas (TOMOVA et al., 2005).

Nos anos 1990, foi reforçado o interesse pelos benefícios da utilização dos óleos essenciais, quando houve a comprovação científica de suas atividades inseticida e repelente contra ampla variedade de pragas (ISMAN; MACHIAL, 2000). Compostos encontrados nos óleos essenciais são altamente bioativos, podem ser muito bem utilizados como inseticidas eficazes e, portanto, devem ser considerados seriamente para o controle de insetos (CHANG et al., 2009). cionamento das glândulas endócrinas que controlam a metamorfose em insetos, bloqueia a síntese e a liberação de hormônios da ecdise (ecditeroides), e, devido à interferência na regulação neuroendócrina de hormônios nas larvas, leva a uma ecdise incompleta em insetos imaturos (VIEGAS-JÚNIOR, 2005). Em fêmeas adultas de insetos, um mecanismo de ação similar leva à esterilidade (ISMAN; MACHIAL, 2006).

Os óleos essenciais agem em geral de forma rápida. Contra algumas pragas é indicativo de modo de ação neurotóxico, havendo evidências da atuação desses compostos no bloqueio dos receptores de octopamina (ENÁN, 2001, 2005), que é um neurotransmissor semelhante à noradrenalina e age como um neurormônio e neuromodulador (BENELLI et al., 2012), controlando os batimentos cardíacos, os movimentos de voo, o comportamento agressivo e o metabolismo dos insetos (ROEDER, 1999; HUSSEIN, 2005). Os óleos essenciais têm um amplo espectro de ação, devido à presença concomitante de vários componentes ativos que atuam de forma sinérgica, dificultando o desenvolvimento de resistência (LEE, 2002).

Em geral, os óleos essenciais das plantas e seus principais componentes, monoterpenos, estão entre as alternativas atualmente disponíveis comercialmente com maior potencial de uso como inseticida botânico (ISMAN; MACHIAL, 
2006; PAVELA et al., 2016). Esses compostos voláteis também induzem alterações de comportamento em insetos e inibem a oviposição na superfície de grãos armazenados (TRIPATHI et al., 2000; VERMA et al., 2000). Além disso, o tratamento de grãos com óleos essenciais na pós-colheita é efetivo na redução da

\subsection{Modo de Ação Desconhecido}

Azadirachta indica (sinonímia Antelaea azadirachta, Melia azadirachta) é uma árvore pertencente à família Meliaceae (mogno), com centros de origem localizados no sul e sudeste da Ásia (SCHMUTTERER, 1990). É uma árvore resistente à seca e pode crescer em diferentes tipos de solo (SCHMUTTERER, 2002).

Mais de 140 princípios ativos foram identificados em diferentes partes da árvore de nim A. indica (KOUL, 2004), embora poucos deles tenham sido testados quanto à sua atividade biológica. Se o material extraído não é extraído das sementes, frutos, folhas e ramos frescos, tais materiais deveriam ser desidratados à temperatura ambiente para evitar decomposição. Geralmente etanol, metanol e acetona são utilizados para extração, visando isolar a azadiractina. Diterpenos, triterpenos, tetraterpenos, meliacinas e outros grupos químicos podem ser obtidos de Meliaceae. Azadiractina é uma meliacina e juntamente com os seus derivados possui ação fagorrepelente em altas concentrações e regulador de cresci- infestação nos galpões e auxilia na redução da disseminação dos insetos dos armazéns para o campo (ISMAN et al., 2001). Doses subletais desses óleos ou seus subprodutos alteram o ciclo reprodutivo, principalmente o controle gonadotrófico em fêmeas adultas, e mostram atividade ovicida (UPADHYAY, 2016).

mento a baixas concentrações (KRAUS, 2002), além de inibir a oviposição.

Extratos de folhas, óleo extraído de sementes, bem como de torta de nim têm ampla aplicação na produção agrícola e pecuária. Possuem ação sobre vírus, bactérias, fungos, nematoides, protozoários, moluscos, insetos e ácaros (SCHMUTTERER, 2002). Azadiractina funciona sistemicamente em plantas, sendo retirado do solo e translocado para as folhas e ramos em crescimento. Quase nenhum outro produto tem essa vantagem (MORGAN, 2004).

Apesar da alta seletividade, os derivados de nim afetam aproximadamente 400 a 500 espécies de insetos pertencentes às Ordens Blattodea, Coleoptera, Dermaptera, Diptera, Ensifera, Hemiptera, Hymenoptera, Isoptera, Lepidoptera, Phasmida, Phthiraptera, Siphonaptera, Thysanoptera e várias espécies de ácaros (KOUL, 2004).

O nim pode provocar outros efeitos, além de alterações na alimentação, metamorfose, fecundidade, esterilidade e postura dos insetos, como redução da 
visão e locomoção em gafanhotos (Orthoptera), percepção de semioquímicos, redução da longevidade, alteração hormonal e nos simbiontes (SCHMUTTERER; WILPS, 2002).
Na tabela 1 estão resumidos os efeitos esperados de extratos botânicos para algumas espécies de artrópodos de importância econômica.

\section{Exemplos de aplicação de extratos naturais e óleos essenciais em Moscas-das-Frutas (Diptera: Tephritidae)}

Diversos óleos essenciais têm atividade inseticida em larvas (EL-SHAZLY; HUSSEIN, 2004) e adultos de Diptera (PALACIOS et al., 2009; CHANG et al., 2009). Óleos essenciais voláteis de Calendula micrantha L. (Astearaceae) mostraram atividade inseticida e inibição do potencial reprodutivo de mosca-do-mediterrâneo C. capitata (HUSSEIN, 2005).

Em testes realizados por BENELLI et al. (2012), foi observada toxidade de óleos essenciais de Rosmarinus officinalis L. (Lamiaceae), Lavandula angustifolia Miller. (Lamiaceae), Hyptis suaveolens L. (Lamiaceae) e Thuja occidentalis L. (Cupressaceae) em adultos de C. capitata, com mortalidade acima de $50 \%$ em teste de ingestão. $O$ óleo essencial de $T$. occidentalis foi o mais tóxico dentre os testados, com $\mathrm{CL}_{50}$ de $5371 \mathrm{ppm}$. CHANG et al. (2009) relataram que o óleo essencial de Ocimum basilicum L. mostrou uma ação tóxica em adultos de C. capitata em ensaios de fumigação.

SALLES; RECH (1999) verificaram que todos os tratamentos de Nim (A. indica) e Cinamomo ( $M$. azedarach) produziram adultos de $A$. fraterculus deformados, sendo que esses insetos não expandiram normalmente as asas. $O$ mes- mo efeito inseticida provocado pelo Nim foi observado por STARK et al. (1990) em C. capitata, Dacus dorsalis Hendel e Dacus cucurbitae Coquillett. Pupários deformados, caracterizados pela aparência larviforme, indicam a interferência desses produtos no desenvolvimento larval e no pupamento (SALLES; RECH, 1999).

Em estudos feitos por BUENTELLO-WONG et al., (2016), o óleo essencial de Eugenia caryophyllus L. foi tóxico a adultos de Anastrepha ludens (Loew) com uma $\mathrm{CL}_{50}$ de 3529 ppm e uma $\mathrm{CL}_{90}$ de 7763 ppm, provavelmente devido ao fato do metil eugenol ser o seu componente principal $(77,58 \%)$. O eugenol é tóxico para diversas espécies de Diptera (BARBOSA et al., 2012), interferindo nos receptores de octopamina, que é um neuromodulador em artrópodes, com influência neuro-hormonal (ENAN, 2005).

Papachristos et al. (2009) reportaram a toxicidade de alguns componentes (linalol, a-terpineol, 4-terpineol e neral), que eram predominantes nos óleos essenciais de Thymus vulgaris L. e Ocimum basilicum L., a larvas de $C$. capitata. Esses monoterpenos oxigenados foram os mais tóxicos de 17 monoterpenos e ses- 
quiterpenos testados contra larvas de $C$. capitata, com valores de $\mathrm{CL}_{50}$ inferiores a $5 \mu \mathrm{l} / \mathrm{g}$ de alimento. O óleo essencial de T. vulgaris possui timol (36.85\%) em sua composição (BUENTELLO-WONG et al., 2016), sendo que há indícios de que o timol atue como modulador alostérico positivo dos receptores de GABA (PRIESTLEY et al., 2003), o que pode explicar a toxidade do óleo essencial de $T$. vulgaris em moscas-das-frutas (BUENTELLO-WONG et al., 2016).

Testes com pulverização de alguns óleos vegetais, na concentração de 10 $\mathrm{mL} / \mathrm{L}$, em frutos de maçã, Malus domestica (Rosaceae), demonstraram que extratos de Carthamus tinctorius, Gossypium herbaceum, Linum usitatissimum, $A$. indica e Elaeis guineensis reduzem significativamente a oviposição de Bactrocera tryoni (Froggatt), sendo que $C$. tinctorius apresentou o melhor resultado, com redução de $56 \%$ na oviposição (HIDAYAT et al., 2013).

Os produtos de Nim foram relatados em vários estudos, por serem ativos contra moscas-das-frutas, incluindo efeitos tóxicos, repelentes e deterrentes de oviposição (MAHMOUD; SHOEIB, 2008).

DORLA et al. (2017) estudaram a toxicidade do óleo essencial de Peperomia borbonensis (Piperaceae) e seus componentes principais, isolados ou combinados, a Bactrocera cucurbitae (Coquillett). Tais compostos parecem agir como neurotoxinas, após o contato com adultos de $B$. cucurbitae que apresentavam convulsões e queda. A mortalidade foi observada a partir da dose de $0,12 \mathrm{mg} / \mathrm{cm}^{2}$ e os valores de $\mathrm{DL}_{50}$ e $\mathrm{DL}_{90}$, para a exposição por $180 \mathrm{~min}$, foram de $0,23 \mathrm{mg} / \mathrm{cm}^{2} \mathrm{e}$ 0,34 mg/cm² (DORLA et al., 2017).

CHANG et al. (2009) avaliaram o potencial tóxico do óleo de manjericão (Ocimum basilicum $\mathrm{L}$.) e seus principais constituintes (trans-anetol, estragol e linalol), em três espécies de moscas-das-frutas: C. capitata, Bactrocera dorsalis (Hendel) e B. cucurbitae. Estragol e linalol tiveram ação inseticida mais rápida para $B$. dorsalis, sendo que, no geral, $C$. capitata e $B$. dorsalis foram mais suscetíveis ao trans-anethol, estragol, linalol e óleo de manjericão do que $B$. cucurbitae. As taxas de knockdown, seguidas de morte, após duas horas de exposição a linalol a $10 \%$, foram de $65 \%, 67 \%$ e $100 \%$ para B. cucurbitae, B. dorsalis e C. capitata, respectivamente.

Extratos naturais de Cinamomo ( $M$. azedarach), Cambará (Lantana camara L.), Alho (Allium sativum L.) e açafrão-da-terra (Curcuma longa L.) se mostraram capazes de reduzir a oviposição de Bactrocera tau (Walker) e B. cucurbitae. Allium sativum e $M$. azedarach reduziram a oviposição em 84,7 e $83,9 \%$ em B. tau e 83,5 e $83,0 \%$ em $B$. cucurbitae, respectivamente (THAKUR; GUPTA, 2013). SINGH; SRIVASTVA (1983) reportaram resultados semelhantes para Nim quanto à diminuição na taxa de oviposição de $B$. cucurbitae, com influência no desenvolvimento e na reprodução dos insetos (ISMAN; MACHIAL, 2006).

Na tabela 2 estão resumidos os efeitos esperados de extratos botânicos para algumas espécies de moscas-das-frutas de importância econômica. 


\section{Considerações finais}

A necessidade de mais estudos sobre o potencial das espécies vegetais como fontes de extratos naturais para o controle de insetos-praga é evidente, especialmente, para as espécies de moscas-das-frutas de importância econômica. A biodiversidade da flora brasileira permite maiores esforços na prospecção de compostos bioativos e pode contribuir significativamente no controle de insetos-praga. Os estudos com metabolitos secun- dários mostram resultados satisfatórios na repelência, deterrência alimentar e de oviposição e mortalidade das principais espécies-praga da horticultura. A busca por novas alternativas para o controle e manejo de insetos, incluindo tefritídeos, não é novidade, mas precisa resultar em inovação, auxiliando a adoção de novas técnicas de manejo, suprindo demandas para a segurança alimentar e ambiental.

\section{Referências}

ALKOFAHI, A.; RUPPRECHT, J.K.; ANDERSON, J.E.; MCLAUGHLIN, J.L.; MIKOLAJCZAK, K.L.; SCOTT, B.A. Search for new pesticides from higher plants. Insecticides of Plant Origin, ACS Symposium Series 387, Washington, v.3, p.24-25, 1987.

ALMEIDA, J.C.; SGROTT, T.L.; SOUSA, M.A. O prejuízo causado pelos agrotóxicos para a efetivação da sustentabilidade. Revista Eletrônica de Iniciação Científica. Itajaí, Centro de Ciências Sociais e Jurídicas da UNIVALI. v.6, n.1, p.99-112, $1^{\circ}$ Trimestre de 2015. Disponível em: www.univali.br/ricc - ISSN 2236-5044.

ALUJA, M.; NORRBOM, A.L. (eds.) Fruit Flies (Tephritidae): Phylogeny and evolution of behavior. Boca Raton, FL: CRC Press, 963p., 2000.

BALLESTA-ACOSTA, M.C.; PASCUAL-VILLALOBOS, M.J.; RODRÍGUEZ, B. The antifeedant activity of natural plant products towards the larvae of Spodoptera littoralis. Spanish Journal of Agricultural Research, v.6, n.1, p.85-91, 2008.

BARBOSA, J.D.; SILVA, V.B.; ALVES, P.B. Structure-activity relationships of eugenol derivatives against, Aedes aegypti (Diptera: Culicidae) larvae. Pest Management Science, v.68, n.6, p.1478-1483, 2012.

BECERRA, J.X. Insects on plants: macroevolutionary chemical trends in host use. Journal Science, USA, v.276, n.5310, p.253-56, 1997.

BEGUM, N.; SHARMA, B.; PANDEY, R.S. Evaluation of insecticidal efficacy of Calotropis procera and Annona squamosa ethanol extracts against Musca domestica. Journal of Biofertilizers \& Biopesticides, v.1, n.1, p.101-105, 2010. 
BEGUM, N.; SHARMA, B.; PANDEY, R.S. Evaluation of insecticidal efficacy of Calotropis procera and Annona squamosa ethanol extracts against Musca domestica. Journal of Biofertilizers \& Biopesticides, India, v.1, n.1, p.1-6, 2010.

BÉLO, M.; BARBOSA, J.C.; PEREIRA, P.S.; BERTONI, B.W.; ZINGARETTI, S.M.; BELEBONI, R.O. Avaliação do efeito bioinseticida dos extratos de Tabernaemontana catharinensis A.DC. (Apocynaceae) e Zeyheria montana Mart. (Bignoniaceae) sobre a mosca Zaprionus indianus (Diptera: Drosophilidae) (Gupta, 1970). Revista Brasileira de Biociências, Porto Alegre, v.7, n.3, p.235-239, 2009.

BENELLI, G.; FLAMINI, G.; CANALE, A.; CIONIB, P. L.; DEMIA, F.; CECCARINIC, L.; MACCHIAC, M.; CONTIA, B. Toxicity of some essential oil formulations against the Mediterranean fruit fly, Ceratitis capitata (Wiedemann) (Diptera Tephritidae). Crop Protection, v.42, n.1, p.223229, 2012.

BEN-KHALIFA, N.E.; CHAIEB, I.; LAARIF, A.; HAOUALA, R. Insecticidal activity of six Apiaceae essential oils against Spodoptera littoralis Boisduval (Lepidoptera: Noctuidae). Journal of New Sciences, Agriculture and Biotechnology, v.55, n.1, p.3603-3609, 2018.

BERNAYS, E.A.; GRAHAM, M. On the evolution of host specificity in phytophagous arthropods. Ecology, California, v.69, n.4, p.886-92, 1988.

BLÄSKE, V.U.; HERTEL, H.; FORSCHLER, B.T. Repellent effects of isoborneol on subterranean termites (Isoptera: Rhinotermitidae) in soils of different composition. Journal of Economic Entomology, v.9, n.64, p.1267-1274, 2003.

BOGGS, C.L. Understanding insect life histories and senescence through a resource allocation lens. Functional Ecology, v.23, n.1, p.27-37, 2009.

BOIÇA JÚNIOR, A.L.; SOUZA, B.H. de.; COSTA, E.N.; RIBEIRO, Z.A.; STOUT, M.J. Factors influencing antixenosis in soybean to Anticarsia gemmatalis and Spodoptera frugiperda (Lepidoptera: Noctuidae). Journal of Economic Entomology, v.108, n.1, p.317-325, 2015.

BONALDO, S.M.; SCHWAN-ESTRADA, K.R.F.; STANGARLIN, J.R.; TESSMANN, D.J.; SCAPIM, C.A. Fungitoxicidade, atividade elicitora de fitoalexinas e proteção de pepino contra Colletotrichum lagenarium, pelo extrato aquoso de Eucalyptus citriodora. Fitopatologia Brasileira, São Paulo, v.29, n.2, p.128-134, 2004.

BRATTSTEN, L.B.; HOLYOKE, C.W.; LEEPER, J.R. Insecticide resistance: challenge to pest management and basic research. Science, v.231, n.1, p.1125-1128, 1986.

BUENTELLO-WONG, S.; GALÁN-WONG, L.; ARÉVALO-NIÑO, K.; ALMAGUER-CANTÚ, V.; ROJAS-VERDE, G. Toxicity of some essential oil formulations against the Mexican fruit fly Anastrepha ludens (Loew) (Diptera: Tephritidae). Industrial Crops and Products, EUA, v.85, n.1, p.58-62, 2016.

BUSS, E.A.; PARK-BROWN, S.G. Natural products for insect pest management. Gainesville: UF/IFAS, p.1-8, 2002. Disponível em: http://edis.ifas.ufl.edu/IN197. Acesso em: 2 fev. 2018. 
CASIDA, J.E.; QUISTAD, G.B. Golden age of insecticide research: past, present or future? Annual Review of Entomology, v.43, p.1-16, 1998.

CASTILHOS, R.V.; GRÜTZMACHER, A.D.; COATS, J.R. Acute toxicity and sublethal effects of terpenoids and essential oils on the predator Chrysoperla externa (Neuroptera: Chrysopidae). Neotropica Entomology, v.47, n.1, p.311-317, 2018.

CAVALCANTE, G.M.; MOREIRA, A.F.B.; VASCONCELOS, S.D. Potencialidade inseticida de extratos aquosos de essências florestais sobre mosca-branca. Pesquisa Agropecuária Brasileira, v.41, n.1, p.9-14, 2006.

CHANG, C.L.; CHO, I.K.; LI, Q.X. Insecticidal activity of basil oil, trans-anethole, estragole, and linalool to adult fruit flies of Ceratitis capitata, Bactrocera dorsalis and Bactrocera cucurbitae. Journal of Economic Entomology, v.102, n.1, p.203-209, 2009.

CORREAA, J.C.R.; SALGADO, H.R.N. Atividade inseticida das plantas e aplicações: revisão. Revista Brasileira de Plantas Medicinais, v.13, n.4, p.500-506, 2011.

DAIDO, M.; FUKAMIYA, N.; OKANO, M.; TAGAHARA, K.; HATAKOSHI, M.; YAMAZAKI, H. Antifeedant and insecticidal activity of quassinoids against Diamondback Moth (Plutella $x y-$ lostella). Bioscience Biotechnology and Biochemistry, Tokyo, v.57, n.2, p.244-246, 1993.

DEDERER, H.; WERR, M.; IIG, T. Differential sensitivity of Ctenocephalides felis and Drosophila melanogaster nicotinic acetylcholine receptor $\alpha 1$ and $\alpha 2$ subunits in recombinant hybrid receptors to nicotinoids and neonicotinoid insecticides. Insect Biochemistry and Molecular Biology, v.41, n.1, p.51-61, 2011.

DEQUECH, S.T.B.; SAUSEN, C.D.; LIMA, C.G.; EGEWARTH, R. Efeito de extratos de plantas com atividade inseticida no controle de Microtheca ochroloma Stal (Col.: Chrysomelidae), em laboratório. Revista Biotemas, 21, n.1, p.41-46, 2008.

DI RENZO, G. Ryanodine receptor agents. XPharm: The comprehensive pharmacology reference. p.1-5, 2009. doi:10.1016/b978-008055232-3.63834-6.

DORLA, E.; GAUVIN-BIALECKI, A.; DEUSCHER, Z. Insecticidal activity of the leaf essential oil of Peperomia borbonensis MIQ. (Piperaceae) and its major components against the melon fly Bactrocera cucurbitae (Diptera: Tephritidae). Chemistry \& Biodiversity, Zurich, v.14, n.1, p.1-9, 2017.

EL-SHAZLY, A.M.; HUSSEIN, K.T. Chemical analysis and biological activities of the essential oil of Teucrium leucocladum Boiss. (Lamiaceae). Biochemical Systematics and Ecology, v.32, n.7, p.665-674, 2004.

ENAN, E.E. Insecticidal activity of essential oils: octopaminergic sites of action. Comparative Biochemistry Physiology - Part C: Toxicology Pharmacology, v.130, p.325-337, 2001. 
ENAN, E.E. Molecular and pharmacological analysis of an octopamine receptor from american cockroach and fruit fly in response to plant essential oils. Archives of Insect Biochemistry and Physiology, v.59, p.161-171, 2005.

EVANS, D.A. KALEYSA, R.R. Effect of quassin on the metabolism of catecholamines in different life cycle stages of Culex quinquefasciatus. Indian Journal of Biochemistry \& Biophysics, v.29, n.4, p.360-3, 1992.

EVANS, D.A.; RAJ, R.K. Quassin: A mosquito larvicide with selective toxicity. Journal of Ecotoxicology \& Environmental Monitoring, v.1, n.4, p.243-249, 1991.

FARRELL, B.D.; MITTER, C.; FUTUYMA, D.J. Diversification at the insect-plant interface. Insight from phylogenetics. BioScience, v.42, n.1, p.34-42, 1992.

FERNANDES, M.C.A.; RIBEIRO, R.L.D.; AGUIAR-MENEZES, E.L. Manejo agroecológico de fitoparasitas. In: AQUINO, A.M. de; ASSIS, R.L. (Ed.). Agroecologia: Princípios e técnicas para uma agricultura orgânica sustentável. Brasília, DF: Embrapa Informação Tecnológica, 273322p., cap.13, 2005.

FERRACINI, V.L.; CAPALBO, D.M.F.; NARDO, E.A.B. DE; ZAVATTI, L.M.S.; SAITO, M.L.; FRIGHETTO, R.T.S.; SCRAMIN, S.; CANUTO, J.C.; LIMA, E. DE S.; SISCARO, M.T.; SILVA, S.R. DA.; SOUZA, L.G.A. DE.; RIZZOLI, P.R.; STEFANUTO, M.A. Apresentação In: WORKSHOP SOBRE PRODUTOS NATURAIS NO CONTROLE DE PRAGAS, DOENÇAS E PLANTAS DANINHAS, Anais, 1990, Jaguariúna, SP: Embrapa/CNPDA, p.11-12, 1990.

FERREIRA, M.L.P.C. A pulverização aérea de agrotóxicos no Brasil: cenário atual e desafios. Revista de Direito Sanitário, v.15, n.3, p.18-45, 2015.

FITT, G.P. The influence of a shortage of hosts on the specificity of oviposition behaviour in species of Dacus (Diptera: Tephritidae). Physiological Entomology, v.11, n.1, p.133-43, 1986.

GALLO, L.G.; ALLEE, L.L.; GIBSON, D.M. Insecticidal effectiveness of Mammea americana (Guttiferae) extracts on larvae of Diabrotica virgifera (Coleoptera: Chrysomelidae) and TrichopIusia ni (Lepidoptera: Noctuidae). Journal Economic Botany, v.50, n.2, p.236-242, 2002.

GARCIA, M.; GONZALEZ, S.M.; PAZOS, L. Actividad farmacológica del extracto acuoso de madera de Quassia amara (Simarubaceae) en ratas y ratones albinos. Revista de Biologia Tropical, v.45, p.47-50, 1996.

GHABBARI, M.; GUARINO, S.; CALECA, V.; SAIANO, F.; SINACORI, M.; BASER, N.; JEMÂA, J. M.; LO VERDE, G. Behavior-modifying and insecticidal effects of plant extracts on adults of Ceratitis capitata (Wiedemann) (Diptera Tephritidae). Journal of Pest Science, v. 91, n.1, p.907-917, 2018.

GOVINDARAJAN, M. Larvicidal and repellent activities of Sida acuta Burm. F. (Family: Malvaceae) against three important vector mosquitoes. Asian Pacific Journal of Tropical Medicine, v.3, n.9, p.691-695, 2010. 
GOVINDARAJAN, M.; VASEEHARAN, B.; ALHARBI, N.S.; KADAIKUNNAN, S.; KHALED, J.M.; AL-ANBR, M.N.; ALYAHYA, S.A.; MAGGI, F.; BENELLI, G. High efficacy of (Z)-y-bisabolene from the essential oil of Galinsoga parviflora (Asteraceae) as larvicide and oviposition deterrent against six mosquito vectors. Science and Pollution Research, v.1, n.1, p.1-13, 2018.

GUEDES, A.G.L. Timbó (Derris urucu): defensivo alternativo para uso em agricultura. Agroecologia Hoje, v.1, n.6, p. 18-19, 2001.

GUPTA, A.; UPADHYAY, R.K.; SAXENA, P.N. Toxicity evaluation of certain blood biochemical parameters in Passer domesticus (Linn.). Journal of Scientific and Industrial Research, v.60, n.1, p.668-674, 2001.

HARBORNE, J.B. (4 ed.). Introduction to Ecological Biochemistry. Londres: Harcourt Brace and Company, 318p.1993.

HARUTA, M.; MAJOR, I.T.; CHRISTOPHER, M.E.; PATTON, J.J.; CONSTABEL, C.P. A Kunitz trypsin inhibitor gene family from trembling aspen (Populus tremuloides Michx.): cloning, functional expression, and induction by wounding and herbivory. Plant Molecular Biology, v.46, n.1, p. 347-359, 2001.

HEINZ, S.; FREYBERGER, A.; LAWRENZ, B.; SCHLADT, L.; SCHMUCK, G.; ELLINGER-ZIEGELBAUER, $\mathrm{H}$. Mechanistic investigations of the mitochondrial complex i inhibitor rotenone in the context of pharmacological and safety evaluation. Scientific Reports, v.7, n.45465, 2017. Disponível em: https://www.nature.com/articles/srep45465. Acesso em: 25 ago. 2018.

HERMSMEIER, D.; SCHITTKO, U.; BALDWIN, I.T. Molecular interactions between the specialist herbivore Manduca sexta (Lepidoptera, Sphingidae) and its natural host Nicotiana attenuate: I. Large-scale changes in the accumulation of growth and defense-related plant mRNAs. Journal of Plant Physiology, v.125, n.2, p.683-700, 2001.

HIDAYAT, Y.; HEATHER, N.; HASSAN, E. Repellency and oviposition deterrence effects of plant essential and vegetable oils against female Queensland fruit fly Bactrocera tryoni (Froggatt) (Diptera: Tephritidae). Australian Journal of Entomology, v.52, n.1, p.379-386, 2013.

HOSSAIN, S.; KHALEQUZZAMAN, M. Repellent and oviposition deterrent activity of leaf extracts of Azadirachta indica A. Juss., Persicaria hydropiper (L.) Spach. and Vitex negundo Linn. against the melon fruit fly, Bactrocera cucurbitae (Coquillett) (Diptera: Tephritidae). Journal of Entomology and Zoology Studies, v.6, n.2, p.2291-2292, 2018.

HUSSEIN, K.T. Supressive effects of Calendula micrantha oil and gibberelic acid (PGR) on reproductive potential of the Mediterranean fruit fly Ceratitis capitata Wied. (Diptera: Tephritidae). Journal of the Egyptian Society of Parasitology, v.35, n.2, p.365-377, 2005.

IKBAL, C.; BEN, H.K.; BEN, H.M. Insect growth regulator activity of Cestrum parqui saponins: an interaction with cholesterol metabolism. Communications in Agricultural and Applied Biological Sciences, v.71, n.2, p.489-496, 2006. 
ILYAS, A.; KHAN, H.A.A.; QADIR, A. Effect of essential oils of some indigenous plants on settling and oviposition responses of peach fruit fly, Bactrocera zonata (Diptera: Tephritidae). Pakistan Journal of Zoology, v.49, n.5, p.1547-1553, 2017.

ISMAN, M.B. Neem and other botanical insecticides: barriers to commercialization. Phytoparasitica, v.25, n.4, p.339-344, 1991.

ISMAN, M.B.; MACHIAL, C.M. Pesticides based on plant essential oils: from traditional practice to commercialization. In: RAI M.; CARPINELLA, C.M. (Eds). Naturally occurring bioactive compounds. Elsevier, Amsterdam, v.3, n.1, p.29-44, 2006.

ISMAN, M.B.; WAN, A.J.; PASSREITER, C.M. Insecticidal activity of essential oils to the tobacco cutworm, Spodoptera litura. Fitoterapia, v.72, n.1, p.65-68, 2001.

JACOBSON, M. Botanical pesticides (past, present and future). In: ANARSON, J.T.; PHILOGENE, B.J.R.; MORAND, P. (Ed.). Insecticides of plant origin. Washington: Annual of Chemistry Society, p.213, 1989.

JACOBSON, M. Insecticides from plants: A review of the literature 1954-1971. Agriculture Handbook, Washington, DC: USDA, n.461. 1975.

KABERA, J.; GASOGO, A.; UWAMARIYA, A.; UGIRINSHUTI, V.; NYETERA, P. Insecticidal effects of essential oil of Pelargonium graveolens and Cymbopogon citratus on Sitophilus zeamais (Motsch.). African Journal of Food Science, v.5, n.6, p.366-375, 2011.

KATHRINA, G.A.; ANTONIO, L.O.J. Controle biológico de insectos mediante extractos botánicos. In: CARBALL, M.; GUAHARAY, F. Control biológico de plagas agrícolas. (Ed.). Managua: CATIE, 2004, p.137-160. (Serie Técnica. Manual Técnico/CATIE,53).

KHAN, S.; AHMAD, R.; SHAH, M.M.; HAQ, I. The insecticidal potential of botanical extracts for management of Peach fruit fly, Bactrocera zonata Saunders, 1842 (Diptera: Tephritidae). Türkiye Entomologi Dergisi, v.40, n.4, p.445-453, 2016.

KONSTANTOPOULOU, M.A.; KROKOS, F.D.; MAZOMENOS, B.E. Chemical composition of corn leaf essential oils and their role in the oviposition behavior of Sesamia nonagrioides females. Journal of Chemical Ecology, v.30, n.1, p.2243-2256, 2002.

KOSHIYA, D.J.; GHELANI, D. Antifeedant activity of different plant derivatives against Spodoptera litura on groundnut. Indian Society of Tobacco Science, v.3, n.1, p.270-275, 1993.

KOUL, O. A global perspective. p.1-19. In: KOUL, O; WAHAB, S. (eds.). Neem: Today and in the New Millennium. Dordrecht: Kluwer Academic Publishers, 276p., 2004.

KRAUS, W. Azadirachtin and other triterpenoids - Part I. p.39-78. In: SCHMUTTERER, H. (Ed.). The neem tree Azadirachta indica A. Juss. and other Meliaceous Plants. Mumbai: Neem Foundation, 893p., 2002. 
KUNA, S.; HEAL, R.E. Toxicological and Pharmacological studies on the powered stem of $R y-$ ania speciosa, a plant insecticide. Journal of Pharmacology and Experimental Therapeutics, v.93, n.3, p.407-413, 1948.

LAHM, G.P.; SELBY, T.P.; FREUDENBERGER, J.H.; STEVENSON, T.M.; MYERS, B.J.; SEBURYAMO, G.; SMITH, B.K.; FLEXNER, L.; CLARK, C.E.; CORDOVA, D. Insecticidal anthranilic diamides: a new class of potent ryanodine receptor activators. Bioorganic \& Medicinal Chemistry Letters, v.15, p.4898-4906, 2005.

LEE, S.E. Biochemical mechanisms conferring cross-resistance to fumigant toxicities of essential oils in a chlorpyrifos-methyl resistant strain of Oryzaephilus surinamensis L. (Coleoptera: Silvanidae). Journal of Storage Products Research, v.38, n.4, p.157, 2002.

LIMA, R.K.; CARDOSO, M.G.; MORAES, J.C.; MELO, B.A.; RODRIGUES, V.G.; GUIMARÃES, P.L. Insecticidal activity of long-pepper essential oil (Piper hispidinervum C. DC.) on fall armyworm Spodoptera frugiperda (J.E. Smith, 1797) (Lepidoptera: Noctuidae). Acta Amazonica, v.39, n.2, p.377-382, 2009.

MAGAÑA, C.; HERNÁNDEZ-CRESPO, P.; ORTEGO, F.; CASTAÑERA, P. Resistance to malathion in field populations of Ceratitis capitata. Journal of Economic Entomology, v.100, n.1, p.1836-1843, 2007.

MAHMOUD, M.F.; SHOEIB, M.A. Sterilant and oviposition deterrent activity of neem formulation on peach fruit fly Bactrocera zonata (Saunders) (Diptera: Tephritidae). Journal of Biopesticides, v.1, n.1, p.177-181, 2008.

MAIA, M.F.; MOORE, A. Plant-based insect repellents: a review of their efficacy, development and testing. Malaria Journal, v.10, n.2, p.1-15, 2011.

MANCEBO, F.; HILJE, L.; MORA, G.A.; SALAZAR, R. Antifeedant activity of Quassia amara (Simaroubaceae) extracts on Hypsipyla grandella (Lepidoptera: Pyralidae) larvae. Crop Protection, v.19, n.1, p.301-305, 2000.

MARTINEZ, S.S. O Nim - Azadirachta indica: Natureza, Usos Múltiplos, Produção. Londrina: IAPAR, 142p., 2002.

MATSUMURA, F. Modes of Action of Insecticides, p.105-164. In: MATSUMURA, F. Toxicology of insecticides. 17th. ed. New York and London: Plenum Press, 493p., 1976.

MELLO, M.O.; SILVA-FILHO, M.C. Plant-insect interactions: an evolutionary arms race between two distinct defense mechanisms. Brazilian Journal of Plant Physiology, v.14, n.1, p.7181, 2002.

MENEZES-AGUIAR, E.L. Inseticidas Botânicos: seus princípios ativos, modo de ação e uso agrícola. (Documentos, 205). Seropédica: Embrapa Agrobiologia, vol.10, n.2, p.58, 2005.

MIGUEL, E.G.; FERREIRA, L.R.; DONEGA, M.A.; DIAS-ARIEIRA, C.R. Atividade de extratos de nim (Azadirachta indica) sobre o crescimento de Colletotrichum spp. Summa Phytopatho- 
logica, v.32, p.18, 2006. Suplemento. Trabalho apresentado no CONGRESSO PAULISTA DE FITOPATOLOGIA, 29, 2006, Botucatu. Resumos. Botucatu, Resumo 34, 2006.

MIGUEL, M.S. Desenvolvimento de fitoterápicos. São Paulo: Robe, p.98, 1999.

MILLS, C.; CLEARY, B.J.; GILMER, J.F.; WALSH, J.J. Inhibition of acetylcholinesterase by tea tree oil. Journal of Pharmacy and Pharmacology, v.56, n.4, p.375-379, 2004.

MONTES, S.M.N.M.; RAGA, A. Eficácia de atrativos para monitoramento de Ceratitis capitata (Diptera: Tephritidae) em pomar citros. Arquivos do Instituto Biológico, v.73, n.3, p. 317-323, 2006.

MORAIS, S.M.; CAVALCANTI, E.S.; BERTINI, L.M.; OLIVEIRA, C.L.L.; RODRIGUES, J.R.B.; CARDOSO, J.H.L. Larvicidal activity of essential oils from Brazilian Crotons species against Aedes aegypti L. Journal of the American Mosquito Control Association, EUA, v.22, n.1, p.161164, 2006.

MOREIRA, M.D.; PICANÇO, M.C.; SILVA, E.M.; MORENO, S.C.; MARTINS, J.C. Uso de inseticidas botânicos no controle de pragas, p.89-120. In: ALVARES, L.; ANDRADE, L.M (coord.). Controle alternativo de pragas e doenças. Viçosa: EPAMIG/CTZM: UFV, 2006.

MORGAN, E.D. The place of neem among modern natural pesticides, p. 21-32. In: KOUL, O; WAHAB, S. (eds.). Neem: today and in the new millennium. Dordrecht: Kluwer Academic Publishers, 276p., 2004.

NAUEN, R. Insecticide mode of action: return of the ryanodine receptor. Pest Management Science, v.62, n.8, p.690-692, 2006.

NIRMA, C.; RODRIGUES, A.M.; BASSET, C.; CHEVOLOT, L.; GIROD, R.; MORETTI, C.; STIEN, D.; DUSFOUR, I.; EPARVIER, V. Larvicidal activity of isoflavonoids from Muellera frutescens extracts against Aedes aegypti. Natural Product Communications, v.7, n.10, p.13191322, 2012.

PACAN, C.; LOUSTALOT, A.J. Comparison of chemical values with the toxicological rotenone equivalent of Derris and Lonchocarpus roots. Journal of Agricultural Research, v.78, n.7, p.197-205, 1949.

PALACIOS, S.M. BERTONI, A.; ROSSI, Y.; SANTANDER, R.; URZÚA, A. Efficacy of essential oils from edible plants as insecticides against the house fly Musca domestica L. Journal Molecules, v.14, p.1938-1947, 2009.

PANDA, N.; KHUSH, G.S. Host plant resistance to insects. Bulletin of Entomological Research, v.86, n.1, p.315-3, 1995.

PAPACHRISTOS, D.P.; KIMBARIS, A.C.; PAPADOPOULOS, N.T. Toxicity of citrus essential oils against Ceratitis capitata (Diptera: Tephritidae) larvae. Annals of Applied Biology, v.155, n.3, p.381-389, 2009. 
PARÉ, P.W.; TUMLINSON, J.H. Plant volatiles as a defense against insect herbivores. Journal of Plant Physiology. v.121, n.1, p.325-331, 1999.

PARK, C.G.; JANG, M.; SHIN, E.; KIM, J. Myrtaceae plant essential oils and their $\beta$-triketone components as insecticides against Drosophila suzukii, Journal Molecules, v.22, n.1050, p.110, 2017.

PAVELA, R.; STEPANYCHEVA, E.; SHCHENIKOVA, A.; CHERMENSKAYA, T.; PETROVA, M. Essential oils as prospective fumigants against Tetranychus urticae Koch. Industrial Crops and Products, v.94, n.1, p.755-761, 2016.

PRIESTLEY, C.M.; WILLIAMSON, E.M.; WAFFORD, K.A.; SATTELLE, D.B. Thymol, a constituent of thyme essential oil, is a positive allosteric modulator of human $\mathrm{GABA}(\mathrm{A})$ receptors and a homo-oligomeric GABA receptor from Drosophila melanogaster. British Journal of Pharmacology, v.140, n.8, p.1363-1372, 2003.

PROKOPY, R.J.; POWERS, P.J. Influence of neem seed extract on oviposition and mortality of Conotrachelus nenuphar (Col., Curculionidae) and Rhagoletis pomonella (Dip., Tephritidae) adults. Journal of Applied Entomology, v.119, n.1, p.63-65, 1995.

RAGA, A.; SATO, M.E. Controle químico de moscas-das-frutas. Documento Técnico 20. São Paulo: Instituto Biológico, p.1-14, 2016. Disponível em: <http://www.biologico.sp.gov.br/docs/ $\mathrm{dt} /$ moscas_das_frutas.pdf>. Acesso em: 16 de dezembro de 2017.

RATTAN, R.S. Mechanism of action of insecticidal secondary metabolites of plant origin. Crop Protection, v.29, n.1, p.913-920, 2010.

RIBEIRO, L.P.; BIERMANN, A.C.S.; DORNELES, M.P.; VENDRAMIM, J.D. Ação de inseticidas botânicos sobre o curuquerê-da-couve. Agropecuária Catarinense, v.29, n.2, p.84-89, 2016.

ROARK, R.C. Some promising insecticidal plants. Journal Economic Botany, v.1, n.1, p.437445, 1947.

ROEDER T. Octopamina em invertebrados. Progress in Neurobiology, v.59, n.5, p.533, 1999.

ROEDER, T. Biogenic amines and their receptors in insects. Comparative Biochemistry and Physiology, v.107, n.1, p.1-12, 1994.

ROHDE, C.; MOINO JÚNIOR, A.; SILVA, P.K.; RAMALHO, K.R.O. Efeito de extratos vegetais aquosos sobre a mosca-das-frutas Ceratitis capitata (Wiedemann) (Diptera: Tephritidae). Arquivos do Instituto Biológico, v.80, n.4, p. 407-415, 2013.

SAAD, K.A.; IDRIS, A.B.; MOHAMAD-ROFF, M.N.; Toxic, repellent, and deterrent effects of citronella essential oil on Bemisia tabaci (Hemiptera: Aleyrodidae) on chili plants. Journal of Entomological Science, v.52, n.2, p.16-52, 2017. 
SALLES, L.A.; RECH, N.L. Efeito de extratos de nim (Azadirachta indica) e cinamomo (Melia azedarach) sobre Anastrepha fraterculus (Wied.). Revista Brasileira de Agrociência, v.5, n.3, p.225-227, 1999.

SANDOVAL-MOJICA, A.F.; CAPINERA, J.L. Antifeedant effect of commercial chemicals and plant extracts against Schistocerca americana (Orthoptera: Acrididae) and Diaprepes abbreviates (Coleoptera: Curculionidae). Pest Management Science, v.67, n.7, p.860-868, 2011.

SANTIAGO, G.P.; PÁDUA, L.E. DE M.; SILVA, P.R.R.; CARVALHO, E.M.S.; MAIA, C.B. Efeitos de extratos de plantas na biologia de Spodoptera frugiperda (J.E. Smith, 1797) (Lepidoptera: Noctuidae) mantida em dieta artificial. Ciência Agrotécnica, v.32, n.3, p.792-796, 2008.

SANTOS, O.O.; MELO, E.A.S.F.; ROCHA, R.B.; OLIVEIRA, R.A.; BITTENCOURT, M.A. Atividade inseticida de produtos de origem vegetal sobre moscas-das-frutas (Diptera: Tephritidae) e broca-rajada (Coleoptera: Curculionidae). Magistra, v.24, número especial, p.26-31, 2012.

SAXENA, R.C. Insecticides from neem. In: ARNASON, J.T.; PHILOGENE, B.J.R. MORAND, P. (Ed.). Insecticides of Plant Origin. Washington: American Chemical Society, p.110-135, 1989.

SCHMUTTERER, $\mathrm{H}$. The tree and its characteristics, p.1-37. In: SCHMUTTERER, H. (Ed.) The neem tree Azadirachta indica A. Juss. and other Meliaceous Plants. Mumbai: Neem Foundation, 2002. 893p.

SCHMUTTERER, H. Properties and potential of natural pesticides from the neem tree. Annual Review of Entomology, v.35, p.291-297, 1990.

SCHMUTTERER, H; WILPS, H. Activity (fitness, Mobility, Vigor), p. 229-237. In: SCHMUTTERER, H. (Ed.) The neem tree Azadirachtaindica A. Juss. and other Meliaceous Plants. Mumbai: Neem Foundation, 893p., 2002.

SECOY, D.M.; SMITH, A.E. Use of plants in control of agricultural and domestic pests. Journal Economic Botany, v.37, n.1, p.28-57, 1983.

SEIXAS, P.T.L.; DEMUNER, A.J.; ALVARENGA, E.S.; BARBOSA, L.C.A.; MARQUES, A.; FARIAS, E.S.; PICANÇO, M.C. Bioactivity of essential oils from Artemisia against Diaphania hyalinata and its selectivity to beneficial insects. Scientia Agricola, v.75, n.6, p.519-525, 2017.

SHAHAB-GHAYOOR, H.; SAEIDI, K. Antifeedant activities of essential oils of Satureja hortensis and Fumaria parviflora against indian meal moth Plodia interpunctella Hübner (Lepidoptera: Pyralidae). Entomology, Ornithology \& Herpetology, v.4, n.3, 2015.

SINGH, R.P.; SRIVASTAVA, B.G. Alcohol extract of neem (Azadirachta indica A. Juss) seed oil as oviposition deterrent for Dacus cucurbitae (Coq.) Indian Journal of Entomology, v.45, n.1, p.497-498, 1983.

SOUZA FILHO, M.F.; RAGA, A.; ZUCCHI, A.R. São Paulo, p.277-283. In: MALAVASI, A.; ZUCCHI, R.A. (eds.). Moscas-das-frutas de importância econômica no Brasil: conhecimento básico e aplicado. Ribeirão Preto, Holos Editora, 2000. 
STARK, J.D.; VARGAS, R.I.; THALMAN, R.H. Azadiracthin effects on metamorphosis, longevity and reproduction of three tephritid fruit fly species (Diptera). Journal of Economic Entomology, v.83, n.6, p. 2168-2174, 1990.

STOWE, K.A. Experimental evolution of resistance in Brassica rapa: correlated response of tolerance in lines selected for glucosinolate content. Evolution, v.52, n.1, p.703-712, 1998.

TADA-OIKAWA, S.; HIRAKU, Y.; KAWANISHI, M.; KAWANISHI, S. Mechanism for generation of hydrogen peroxide and change of mitochondrial membrane potential during rotenone-induced apoptosis. Life Sciences, v.73, n.1, p.3277-3288, 2003.

TAN, J.; GALLIGAN, J.J.; HOLLINGWORTH, R.M. Agonist actions of neonicotinoids on nicotinic acetylcholine receptors expressed by cockroach neurons. Journal Neurotoxicology, v.28, n.4, p.829-42, 2007.

TEIXEIRA, L.A.; ANDALORO, J.T. Diamide insecticides: global efforts to address insect resistance stewardship challenges. Pesticide Biochemistry and Physiology, v.106, n.3, p.76-78, 2013.

THAKUR, M.; GUPTA, D. Plant extracts as oviposition deterrents against fruit flies, Bactrocera spp. infesting vegetable crops. Pesticide Research Journal, v. 25, n.1, p.24-28, 2013.

TOMIZAWA, M.; CASIDA, J.E. Molecular recognition of neonicotinoid insecticides: the determinants of life or death. Accounts of Chemical Research, v.42, n.2, p.260-9, 2009.

TOMOVA, B.S.; WATERHOUSE, J.S.; DOBERSKI, J. The effect of fractionated Tagetes oil volatiles on aphid reproduction. Entomologia Experimentalis et Applicata, v.115, n.1, p.153159,2005

TONG, F.; GROSS, A.D.; DOLAN, M.C.; COATS, J.R. The phenolic monoterpenoid carvacrol inhibits the binding of nicotine to housefly nicotinic acetylcholine receptor. Pest Management Science, v.69, n.7, p.755-780, 2013.

TRIPATHI, A.K.; PRAJAPATI, V.; AGGARWAL, K.K.; KUMAR, S.; KUKREJA, A.K.; DWIVEDI, S.; SINGH, A.K. Effects of volatile oil constituents of Mentha species against the stored grain pests, Callosobruchus maculatus and Tribolium castaneum. Medicinal and Aromatic Plant Science and Biotechnology, v.22, n.1, p.549-556, 2000.

UPADHYAY, R.K. Botanicals; its safe use in pest control and environmental management. International Journal of Zoological Investigations, v.2, n.1, p.58-102, 2016.

VENDRAMIM, J.D.; CASTIGLIONI, E. Aleloquímicos, resistência e plantas inseticidas. In: GUEDES, J.C.; DRESTER DA COSTA, I.; CASTIGLIONI, E. Bases e Técnicas do Manejo de Insetos. Santa Maria: UFSM/CCR, DFS, 113-128p., cap. 8, 2000.

VERMA, N.; TRIPATHI, A.K.; PRAJAPATI, V.; BAHL, J.R.; KHANUJA, S.P.S.; KUMAR, S. Toxicity of essential oil from Lippia alba towards stored grain insects, Journal Medicinal and Aromatic Plant Science and Biotechnology, v.22, n.1, p.50, 2000. 
VIEGAS-JÚNIOR, C. Terpenos com atividade inseticida: uma alternativa no controle de insetos. Química Nova, v.26, n.3, p.390-400, 2003.

WEHLING, W.F.; THOMPSON, J.N. Evolutionary conservatism of oviposition preference in a widespread polyphagous insect herbivore, Papilio zelicaon. Oecologia, v.111, n.2, p.209-215, 1997.

WHEELER, D. The role of nourishment in oogenesis. Annual Review of Entomology, v.41, p.407-431, 1996.

WIESBROOK, M.L. Natural indeed: Are natural insecticides safer and better than conventional insecticides? Illinois Pesticide Review, v.17, n.3, 2004.

WINK, M. Interference of alkaloids with neuroreceptors and ion channels. Studies in Natural Products Chemistry, v.21, n.1, p.3-122, 2000.

ZERA, A.J.; HARSHMAN, L.G. The physiology of life history trade-offs in animals. Annual Review of Ecology and Systematics, v.32, n.1, p.95-126, 2001.

ZETTLER, J.L.; CUPERUS, G.W. Pesticide resistance in Tribolium castaneum (Coleoptera: Tenebrionidae) and Rhyzopertha dominica (Coleoptera: Bostrichidae) in wheat. Journal of Economic Entomology, v.83, n.1, p.1677-1679, 1990.

ZUCCHI, R.A. Taxonomia, p.13-24. In: MALAVASI, A.; ZUCCHI, R.A. (Eds.). Moscas-das-frutas de importância econômica no Brasil: conhecimento básico e aplicado. Ribeirão Preto: Holos Editora, 327p., 2000.

Recebido em: 29/08/2018

Aprovado em: 15/01/2019 
Tabela 1. Tipos de extratos vegetais e seus efeitos em diversas espécies de artrópodes.

\begin{tabular}{|c|c|c|c|c|c|c|c|c|}
\hline Familia Botânica & Nome Cientifico & Parte da Planta & Tipo de extração & Ordem & Nome Cientifico2 & Modo de ação & Fase & Referências \\
\hline Meliaceae & Azadirachta indica & Semente & extrato aquoso & Coleoptera & Conotrachelus nenuphar & Mortalidade/ deterrência de oviposição & Adulto & Prokopy; Powers, 1995 \\
\hline Solanaceae & Nicotiana tabacum & Folha & extrato aquoso & Coleoptera & Microtheca ochroloma & Mortalidade & Adulto/larva & Dequech et al., 2008 \\
\hline Myrtaceae & Leptospermum citratum & Folha & extrato aquoso & Diptera & Drosophila suzukii & Mortalidade & Adulto & Park et al., 2017 \\
\hline Myrtaceae & Leptospermum ericoides & Folha & extrato aquoso & Diptera & Drosophila suzukii & Mortalidade & Adulto & Park et al., 2017 \\
\hline Myrtaceae & Leptospermum scoparium & Folha & extrato aquoso & Diptera & Drosophila suzukii & Mortalidade & Adulto & Park et al., 2017 \\
\hline Lamiaceae & Hyssopus officinalis & Folha & extrato aquoso & Diptera & Drosophila suzukii & Mortalidade & Adulto & Park et al., 2017 \\
\hline Lamiaceae & Lavandula angustifolia & Folha & extrato aquoso & Diptera & Drosophila suzukii & Mortalidade & Adulto & Park et al., 2017 \\
\hline Lamiaceae & Mentha piperita & Folha & extrato aquoso & Diptera & Drosophila suzukii & Mortalidade/repelência & Adulto & Park et al., 2017 \\
\hline Lamiaceae & Ocimum basilicum & Folha & extrato aquoso & Diptera & Drosophila suzukii & Mortalidade & Adulto & Park et al., 2017 \\
\hline Lamiaceae & Origanum majorana & Folha & extrato aquoso & Diptera & Drosophila suzukii & Mortalidade & Adulto & Park et al., 2017 \\
\hline Lamiaceae & Perilla frutescens & Folha & extrato aquoso & Diptera & Drosophila suzukii & Mortalidade & Adulto & Park et al., 2017 \\
\hline Lamiaceae & Salvia sclarea & Folha & extrato aquoso & Diptera & Drosophila suzukii & Mortalidade & Adulto & Park et al., 2017 \\
\hline Lamiaceae & Satureja montana & Folha & extrato aquoso & Diptera & Drosophila suzukii & Mortalidade & Adulto & Park et al., 2017 \\
\hline Lamiaceae & Thymus zygis & Folha & extrato aquoso & Diptera & Drosophila suzukii & Mortalidade & Adulto & Park et al., 2017 \\
\hline Euforbiaceae & Croton zenhtneri & Folha & óleo essencial & Diptera & Aedes aegypti & Mortalidade & Larva & Morais et al., 2006 \\
\hline Euforbiaceae & Croton nepetaefolius & Folha & óleo essencial & Diptera & Aedes aegypti & Mortalidade & Larva & Morais et al., 2006 \\
\hline Euforbiaceae & Croton argyrophyloides & Folha & óleo essencial & Diptera & Aedes aegypti & Mortalidade & Larva & Morais et al., 2006 \\
\hline Euforbiaceae & Croton sonderianus & Folha & óleo essencial & Diptera & Aedes aegypti & Mortalidade & Larva & Morais et al., 2006 \\
\hline Apocynaceae & Calotropis procera & Folha & extrato etanólico & Diptera & Musca domestica & Mortalidade & Larva & Begum et al., 2010 \\
\hline Annonaceae & Annona squamosa & Folha & extrato etanólico & Diptera & Musca domestica & Mortalidade & Larva & Begum et al., 2010 \\
\hline Apocynaceae & Tabernaemontana catharinensis & Casca caule & extrato etanólico & Diptera & Zaprionus indianus & Viabilidade pupal & Pupa & Bélo et al., 2009 \\
\hline Bignoniaceae & Zeyheria montana & Casca caule & extrato etanólico & Diptera & Zaprionus indianus & Viabilidade pupal & Pupa & Bélo et al., 2009 \\
\hline Asteraceae & Galinsoga parviflora & Folha & óleo essencial & Diptera & Aedes aegypti & Toxidade/ deterrência de oviposição & Larva/ adulto & Govindarajan et al., 2018 \\
\hline Asteraceae & Galinsoga parviflora & Folha & óleo essencial & Diptera & Aedes albopictus & Toxidade/ deterrência de oviposição & Larva/ adulto & Govindarajan et al., 2018 \\
\hline Asteraceae & Galinsoga parviflora & Folha & óleo essencial & Diptera & Anopheles stephensi & Toxidade/ deterrência de oviposição & Larva/ adulto & Govindarajan et al., 2018 \\
\hline Asteraceae & Galinsoga parviflora & Folha & óleo essencial & Diptera & Anopheles subpictus & Toxidade/ deterrência de oviposição & Larva/ adulto & Govindarajan et al., 2018 \\
\hline Asteraceae & Galinsoga parviflora & Folha & óleo essencial & Diptera & Culex quinquefasciatus & Toxidade/ deterrência de oviposição & Larva/ adulto & Govindarajan et al., 2018 \\
\hline Asteraceae & Galinsoga parviflora & Folha & óleo essencial & Diptera & Culex tritaeniorhynchus & Toxidade/ deterrência de oviposição & Larva/ adulto & Govindarajan et al., 2018 \\
\hline
\end{tabular}


Tabela 1. Tipos de extratos vegetais e seus efeitos em diversas espécies de artrópodes. (Continuação)

\begin{tabular}{|c|c|c|c|c|c|c|c|c|}
\hline Familia Botânica & Nome Científico & Parte da Planta & Tipo de extração & Ordem & Nome Científico3 & Modo de ação & Fase & Referências \\
\hline Fabaceae & Prosopis juliflora & Folha & extrato aquoso & Hemiptera & Bemisia tabaci & Mortalidade & Ovos/ninfas & Cavalcante et al. 2006 \\
\hline Fabaceae & Leucaena leucocephala & Folha & extrato aquoso & Hemiptera & Bemisia tabaci & Mortalidade & Ovos/ninfas & Cavalcante et al. 2006 \\
\hline Fabaceae & Mimosa caesalpiniifolia & Folha & extrato aquoso & Hemiptera & Bemisia tabaci & Inibição fertilidade & Adulto & Cavalcante et al. 2006 \\
\hline Myrtaceae & Melaleuca alternifolia & Folha & óleo essencial & Hymenoptera & Psyttalia concolor & Mortalidade & Adulto & Benelli et al., 2012 \\
\hline Apiaceae & Carum carvi & Folha & extrato aquoso & Lepidoptera & Spodoptera littoralis & Mortalidade & Larva & Ben-Khalifa et al., 2018 \\
\hline Apiaceae & Cuminum cyminum & Folha & extrato aquoso & Lepidoptera & Spodoptera littoralis & Mortalidade & Larva & Ben-Khalifa et al., 2018 \\
\hline Apiaceae & Daucus carota & Folha & extrato aquoso & Lepidoptera & Spodoptera littoralis & Mortalidade & Larva & Ben-Khalifa et al., 2018 \\
\hline Apiaceae & Foeniculum vulgare & Folha & extrato aquoso & Lepidoptera & Spodoptera littoralis & Mortalidade & Larva & Ben-Khalifa et al., 2018 \\
\hline Apiaceae & Petroselinum crispum & Folha & extrato aquoso & Lepidoptera & Spodoptera littoralis & Mortalidade & Larva & Ben-Khalifa et al., 2018 \\
\hline Asteraceae & Artemisia annua & Ramos & óleo essencial & Lepidoptera & Diaphania hyalinata & Mortalidade & Larva & Seixas et al. 2017 \\
\hline Solanaceae & Nicotiana tabacum & Folha & extrato aquoso & Lepidoptera & Ascia monuste orseis & ovicida/larvicida/deterrência alimentar & Ovo/larva & Ribeiro, 2016 \\
\hline Myrtaceae & Eucalyptus tereticornis & Folha & extrato aquoso & Lepidoptera & Ascia monuste orseis & ovicida/deterrência alimentar & Ovo/larva & Ribeiro, 2016 \\
\hline Fabaceae & Ateleia glazioveana & Folha/ramos & extrato aquoso & Lepidoptera & Ascia monuste orseis & ovicida/deterrência alimentar & Ovo/larva & Ribeiro, 2016 \\
\hline Rutaceae & Ruta graveolens & Folha/ramos & extrato aquoso & Lepidoptera & Ascia monuste orseis & Larvicida & Larva & Ribeiro, 2016 \\
\hline Lamiaceae & Satureja hortensis & Folha & óleo essencial & Lepidoptera & Plodia interpunctella & Deterrência alimentar & Adulto & Shahab-Ghayoor; Saeidi, 2015 \\
\hline Cucurbitaceae & Momordica charantia & Folha/ramos & extrato aquoso & Lepidoptera & Spodoptera frugiperda & Viabilidade larval & Larva & Santiago et al., 2008 \\
\hline Verbenaceae & Lippia sidoides & Folha & extrato aquoso & Lepidoptera & Spodoptera frugiperda & Viabilidade ovos & Ovo & Santiago et al., 2008 \\
\hline Rutaceae & Amyris balsamifera & Folha & óleo essencial & Neuroptera & Chrysoperla externa & Mortalidade & Adulto & Castilho et al., 2018 \\
\hline Lamiaceae & Origanum vulgare & Folha & óleo essencial & Neuroptera & Chrysoperla externa & Mortalidade/redução de fecundidade & Adulto & Castilho et al., 2018 \\
\hline Lamiaceae & Hymus vulgares & Folha & óleo essencial & Neuroptera & Chrysoperla externa & Mortalidade & Adulto & Castilho et al., 2018 \\
\hline Lamiaceae & Ocimum basilicum & Folha & óleo essencial & Trombidiformes & Tetranychus urticae & Inibição fertilidade/viabilidade ovos & Adulto/ovos & Pavela et al., 2016 \\
\hline Lamiaceae & Mentha spicata & Folha & óleo essencial & Trombidiformes & Tetranychus urticae & Inibição fertilidade/viabilidade ovos & Adulto/ovos & Pavela et al., 2016 \\
\hline Lamiaceae & Mentha arvensis & Folha & óleo essencial & Trombidiformes & Tetranychus urticae & Inibição fertilidade/viabilidade ovos & Adulto/ovos & Pavela et al., 2016 \\
\hline Lamiaceae & Mentha pulegium & Folha & óleo essencial & Trombidiformes & Tetranychus urticae & Inibição fertilidade/viabilidade ovos & Adulto/ovos & Pavela et al., 2016 \\
\hline Lamiaceae & Origanum majorana & Folha & óleo essencial & Trombidiformes & Tetranychus urticae & Inibição fertilidade/viabilidade ovos & Adulto/ovos & Pavela et al., 2016 \\
\hline Lamiaceae & Origanum compactum & Folha & óleo essencial & Trombidiformes & Tetranychus urticae & Inibição fertilidade/viabilidade ovos & Adulto/ovos & Pavela et al., 2016 \\
\hline
\end{tabular}


Tabela 2. Tipos de extratos vegetais e seus efeitos em espécies de moscas-das-frutas (Diptera: Tephritidae).

\begin{tabular}{|c|c|c|c|c|c|c|c|}
\hline Familia Botânica & Nome Cientifico & Parte da Planta & Tipo de extração & Nome Cientifico - Inseto & Modo de ação & Fase do Inseto & Referência \\
\hline Meliaceae & Melia azedarach & Fruto & Pó & Anastrepha fraterculus & Viabilidade larval/ viabilidade pupal & Larva/pupa & Salles; Rech, 1999 \\
\hline Meliaceae & Azadirachta indica & Fruto & extratos aquosos & Anastrepha fraterculus & Viabilidades de ovos, larvas, pupas; deterrência de oviposição & Ovo/larva/pupa/adulto & Salles; Rech, 1999 \\
\hline Lamiaceae & Ocimum basilicum & Folha/flor & Óleo essencial & Anastrepha ludens & Mortalidade & Adulto & Buentello-Wong et al., 2016 \\
\hline Myrtaceae & Eugenia caryophyllus & Folha/flor & Óleo essencial & Anastrepha ludens & Mortalidade & Adulto & Buentello-Wong et al., 2016 \\
\hline Lamiaceae & Thymus vulgaris & Folha & Óleo essencial & Anastrepha ludens & Mortalidade & Adulto & Buentello-Wong et al., 2016 \\
\hline Meliaceae & Melia azedarach & Semente & extrato etanólico & Bactrocera cucurbitae & Deterrência de oviposição & Adulto & Thakur; Gupta, 2013 \\
\hline Verbenaceae & Lantana camara & Folha & extrato etanólico & Bactrocera cucurbitae & Deterrência de oviposição & Adulto & Thakur; Gupta, 2013 \\
\hline Liliaceae & Allium sativum & Bulbo & extrato etanólico & Bactrocera cucurbitae & Deterrência de oviposição & Adulto & Thakur; Gupta, 2013 \\
\hline Zingiberaceae & Curcuma longa & Raiz & extrato etanólico & Bactrocera cucurbitae & Deterrência de oviposição & Adulto & Thakur; Gupta, 2013 \\
\hline Lamiaceae & Ocimum basilicum & Folha/flor & Óleo essêncial & Bactrocera curcubitae & Mortalidade & Adulto & Chang et al., 2009 \\
\hline Polygonaceae & Persicaria hydropipe & Folha/flor & extratos aquosos & Bactrocera cucurbitae & Deterrência de oviposição & Adulto & Hossain; Khalequzzaman, 2018 \\
\hline Meliaceae & Azadirachta indica & Folha & extratos aquosos & Bactrocera cucurbitae & Repelência/ deterrência de oviposição & Adulto & Hossain; Khalequzzaman, 2018 \\
\hline Lamiaceae & Ocimum basilicum & Folha/flor & Óleo essencial & Bactrocera dorsalis & Mortalidade & Adulto & Chang et al., 2009 \\
\hline Meliaceae & Melia azedarach & Semente & extrato etanólico & Bactrocera tau & Deterrência de oviposição & Adulto & Thakur; Gupta, 2013 \\
\hline Verbenaceae & Lantana camara & Folha & extrato etanólico & Bactrocera tau & Deterrência de oviposição & Adulto & Thakur; Gupta, 2013 \\
\hline Liliaceae & Allium sativum & Bulbo & extrato etanólico & Bactrocera tau & Deterrência de oviposição & Adulto & Thakur; Gupta, 2013 \\
\hline Zingiberaceae & Curcuma longa & Raiz & extrato etanólico & Bactrocera tau & Deterrência de oviposição & Adulto & Thakur; Gupta, 2013 \\
\hline Lamiaceae & Isodon rugosus & Folha & extrato metanolico & Bactrocera zonata & Mortalidade/repelência & Adulto & Khan et al., 2016 \\
\hline Rutaceae & Boenninghausenia albiflora & Folha & extrato metanolico & Bactrocera zonata & Repelência & Adulto & Khan et al., 2016 \\
\hline Thymelaeaceae & Daphne mucronata & Folha & extrato metanolico & Bactrocera zonata & Mortalidade/Repelência/deterrência de oviposição/viabilidade pupal & Adulto/Pupa & Khan et al., 2016 \\
\hline Asteraceae & Tagetes minuta & Folha & extrato metanolico & Bactrocera zonata & Mortalidade/deterrencia de oviposição/viabilidade pupal & Adulto/Pupa & Khan et al., 2016 \\
\hline Lauraceae & Cinnamomum camphora & Folha & extrato metanolico & Bactrocera zonata & Repelência & Adulto & Khan et al., 2016 \\
\hline Myrtaceae & Eucalyptus sideroxylon & Folha & extrato metanolico & Bactrocera zonata & Mortalidade/deterrência de oviposição/viabilidade pupal & Adulto/Pulpa & Khan et al., 2016 \\
\hline Solanaceae & Datura alba & Folha & Óleo essêncial & Bactrocera zonata & Repelência & Adulto & llyas et al., 2017 \\
\hline Meliaceae & Azadirachta indica & Folha & Óleo essencial & Bactrocera zonata & Deterrência de oviposição & Adulto & llyas et al., 2017 \\
\hline Lamiaceae & Ocimum basilicum & Folha/flor & Óleo essencial & Bactrocera zonata & Atratividade & Adulto & llyas et al., 2017 \\
\hline Meliaceae & Melia azedarach & Folha/Ramo/Fruto & extratos aquosos & Ceratitis capitata & Mortalidade/viabilidade pupal/deterrência alimentar & Adulto/Larva & Rohde et al., 2013 \\
\hline Liliaceae & Allium sativum & Bulbo & extratos aquosos & Ceratitis capitata & Larvicida & Larva & Rohde et al., 2013 \\
\hline Zingiberaceae & Curcuma longa & Raiz & extratos aquosos & Ceratitis capitata & viabilidade pupal & Pulpa & Rohde et al., 2013 \\
\hline Myrtaceae & Melaleuca alternifolia & Folha & Óleo essencial & Ceratitis capitata & Mortalidade & Adulto & Benelli et al., 2012 \\
\hline Lamiaceae & Ocimum basilicum & Folha/flor & Óleo essencial & Ceratitis capitata & Mortalidade & Adulto & Chang et al., 2009 \\
\hline Rutaceae & Ruta graveolens & Folha & extrato etanólico & Ceratitis capitata & Mortalidade & Adulto & Ghabbari et al., 2018 \\
\hline Meliaceae & Azadirachta indica & Semente & extratos aquosos & Rhagoletis pomonella & Mortalidade/ deterrência de oviposição & Adulto & Prokopy; Powers, 1995 \\
\hline
\end{tabular}

